\title{
Constant sickness is not good news
}

\author{
Rowan Davies explains why pregnancy related sickness sucks the joy out of life and led her to \\ consider a termination
}

\section{Rowan Davies}

My first pregnancy was unplanned but welcome. I became hyperemetic quickly. I felt queasy even before the positive pregnancy test result-around week 4 of the pregnancy everything suddenly smelt strongly, and my appetite dropped sharply. By week 5 I had started to vomit more than 20 times a day and I was unable to hold down water or food. Food-the thought of it and the smell of it-was the major trigger. I was so overwhelmingly nauseous that it was difficult to tell what made me sick: it would be easier to list the things that didn't.

Hyperemesis sucks the joy out of life. I couldn't pop out for a coffee, meet friends, look at a computer screen, listen to the radio, have conversations, or read. My world became tiny and bleak. My skin ached, and I have never felt so weak. I thought that I was somehow encouraging or promoting the nausea. It didn't occur to me that I had a recognised medical condition.

\section{Hearing that sickness was "good"}

Over the coming months I heard from a few healthcare professionals that sickness was "good." It's difficult to describe how disorienting this was. I'd never felt so ill in my life, I was desperately upset, and I was already beginning to wonder whether I could continue with the pregnancy. To be told that this was "good" felt strange and unjust. I understood the negative correlation between miscarriage risk and sickness, but nevertheless nothing about the situation felt "good" to me.

Feebly, I tried to explain that the sickness was more than I could cope with. And I was left with the impression that the drug to help with sickness, which I was prescribed, was my only chance if I wanted to keep the pregnancy, because I knew I could not continue with such uncontrolled nausea. When the melt in the mouth pills had done nothing I decided that I needed to book a termination.

\section{Listening and helping}

I am so grateful that I spoke at length to someone about what was going on, and explained that mine was a wanted pregnancy, but that I could not cope like this for another few months. The clinician was clear with me that other drugs were worth trying. The cyclizine they prescribed did not stop the vomiting or the nausea, but it made them bearable. I remained extremely sick until the seventh month of pregnancy, and I gave birth to a healthy baby.

The concept of "good" sickness could imply that a woman should be grateful for such overwhelmingly difficult symptoms, which adds insult and confusion.

\section{What you need to know}

- Women with pregnancy sickness can be exhausted and weak; even if a woman is usually articulate, she may not be in a state that allows her to fully advocate for herself

- Emphasise that if the first approach fails it's not necessarily the end of options

- Be careful with the language that you use around pregnancy related sickness-hyperemesis is an awful experience and is not "great news"

\section{Education into practice}

- How do you explore symptoms of sickness in pregnancy? Given that patients may feel too unwell to offer these are there ways you might alter your questions in particular circumstances?

- Hearing that pregnancy related sickness is "good" was not helpful to this patient. How do you typically frame conversations about sickness in pregnancy? Are there ways in which you might adapt this?

- Pregnancy related sickness might affect women's ability to advocate for themselves, are there ways in which you could help?

Competing interests: $\mathrm{RD}$ is the head of campaigns and policy at mumsnet.com but wrote this article in a personal capacity.

Provenance and peer review: Commissioned; not externally peer reviewed. Published by the BMJ Publishing Group Limited. For permission to use (where not already granted under a licence) please go to http://group.bmj.com/group/rights-licensing/ permissions 